\title{
Caracterização de Fibras de Bananeira e de Coco por Ressonância Magnética Nuclear de Alta Resolução no Estado Sólido
}

\author{
Sandra R. Albinante, Elen B. A. V. Pacheco, Leila L. Y. Visconte, Maria I. B. Tavares \\ Instituto de Macromoléculas Professora Eloisa Mano, UFRJ
}

\begin{abstract}
Resumo: A análise de ressonância magnética nuclear, RMN, de alta resolução no estado sólido permitiu um estudo detalhado da dinâmica molecular de fibras naturais, entre elas duas obtidas a partir do tronco de bananeira e outra, da fruta do coco. Utilizou-se a técnica de relaxação nuclear para avaliar os domínios relacionados às diferentes mobilidades dos componentes dessas fibras, tais como celulose, hemicelulose e lignina. Também foram realizados testes para a quantificação do teor de lignina por método químico. A partir dos tempos de relaxação e da curva de domínios, foi possível verificar que as fibras com alto teor de lignina possuem tempos maiores de relaxação, pois esse componente da fibra apresenta uma estrutura, mais rígida, de anéis aromáticos.
\end{abstract}

Palavras-Chaves: RMN estado sólido, relaxação nuclear, fibras naturais.

\section{Characterization of Banana and Coconut Fibers by High-resolution Nuclear Magnetic Resonance in the Solid State}

Abstract: High-resolution nuclear magnetic resonance analysis, NMR, in the solid-state permitted a detailed molecular dynamic study of natural fibers, including two obtained from the banana tree stems and from coconut fruits. The nuclear relaxation technique was applied to evaluate the domains associated with different mobilities of the fiber components, such as cellulose, hemicellulose and lignin. Experiments were also done to quantify the lignin content using a chemical method. From the relaxation times and the domain curves, fibers with higher lignin content were found to have higher relaxation times, because they present a more rigid structure with aromatic groups.

Keywords: Solid state NMR, nuclear relaxation, natural fibers.

\section{Introdução}

A Ressonância Magnética Nuclear (RMN) é considerada uma espectroscopia de extrema importância e versatilidade para se estudar, em nível molecular, a estrutura e a dinâmica molecular de macromoléculas complexas, como as fibras naturais, por exemplo. Essa técnica permite a caracterização das interações moleculares existentes entre os componentes da fibra natural ${ }^{[1,2]}$. Somando, a relaxometria por RMN é uma técnica importante para caracterização de materiais ${ }^{[3,4]}$.

As fibras naturais têm cinco componentes básicos: celulose, hemicelulose, pectina, lignina e extrativos (gorduras, proteínas e sais inorgânicos). A celulose (40 a 90\% em massa da fibra) é responsável pela resistência das fibras devido ao seu alto grau de polimerização e orientação molecular. É um polímero linear cristalino formado por unidades $\beta$-D-glicopironases unidas por ligações glicosídicas. A hemicelulose (1-30\% em massa) é uma variedade de moléculas complexas, amorfas e de unidades $\beta$-D-xilose, $\beta$-D-manose, $\beta$-D-glicose, $\alpha$-L-arabinose e ácido $\beta$-D-glicurônico. Essas unidades são formadas por cadeias de carbono com um grupo hidroxila, exceto os que podem estar na forma de carbonila ou em ligação hemiacetal. A lignina, segundo maior componente em massa (1-35\% em massa), é uma macromolécula formada por um sistema aromático, reticulado, com elevada massa molar, amorfo e com unidades de fenilpropano (Figura 1$)^{[5,6]}$.

Apesar de o Brasil ser o maior produtor e consumidor mundial de banana, a fibra de bananeira é pouco utilizada e estudada. Setores que vem consumindo essa fibra são o têxtil e o de papel ${ }^{[5]}$. A fibra de bananeira é produzida a partir das bainhas foliares extraídas do pseudocaule da bananeira, que equivale a seu tronco, sendo possível retirar cinco tipos diferentes de fibras, desde a mais áspera até a de textura mais fina ${ }^{[7-9]}$.

Outro setor que vem se desenvolvendo e crescendo é o de compósito, no qual as fibras naturais são utilizadas como carga. Esse crescimento se deve ao fato dessas fibras apresentarem diversos benefícios em relação às fibras sintéticas. $\mathrm{O}$ estudo da estrutura molecular dos componentes da fibra permite o conhecimento de sua estrutura química e, consequentemente, implica em sua melhor utilização como carga em uma matriz apolar, dando origem aos compósitos com melhores propriedades ${ }^{[10-13]}$.

Para saber como os diferentes componentes das fibras estão interagindo entre si, pode-se utilizar a técnica de relaxação nuclear do núcleo de hidrogênio por RMN de sólidos. Uma das maiores dificuldades dessa técnica tem sido a sua baixa sensibilidade, uma vez que as diferenças entre os níveis energéticos nas transições de ressonância magnética nuclear são baixas ocasionando uma diferença de população de spins pequena. No entanto, nos últimos anos têm-se verificado diversos avanços na técnica que tem permitido contornar este problema ${ }^{[14-16]}$.

$\mathrm{Na}$ ressonância, a energia é transferida da radiação de radiofreqüência emitida para o núcleo. Assim, ocorre uma mudança na orientação do spin do núcleo, ou seja, muda a população de spins nos vários níveis de energia. Como a absorção de energia afeta a população de spin nuclear, um fator importante é o modo como ocorre o retorno do núcleo excitado ao estado de equilíbrio. Quando a freqüência de ressonância é retirada os núcleos excitados voltam ao estado fundamental emitindo energia na região de radiofreqüência. Este processo de retorno ao equilíbrio é denominado de processo de relaxação. Os processos

Autor para correspondência: Elen B. A. V. Pacheco, Instituto de Macromoléculas Professora Eloisa Mano, Universidade Federal do Rio de Janeiro - UFRJ, Bloco J, CP 68525, CEP 21945-970, Rio de Janeiro, RJ, Brasil, e-mail: elen@ima.ufrj.br 


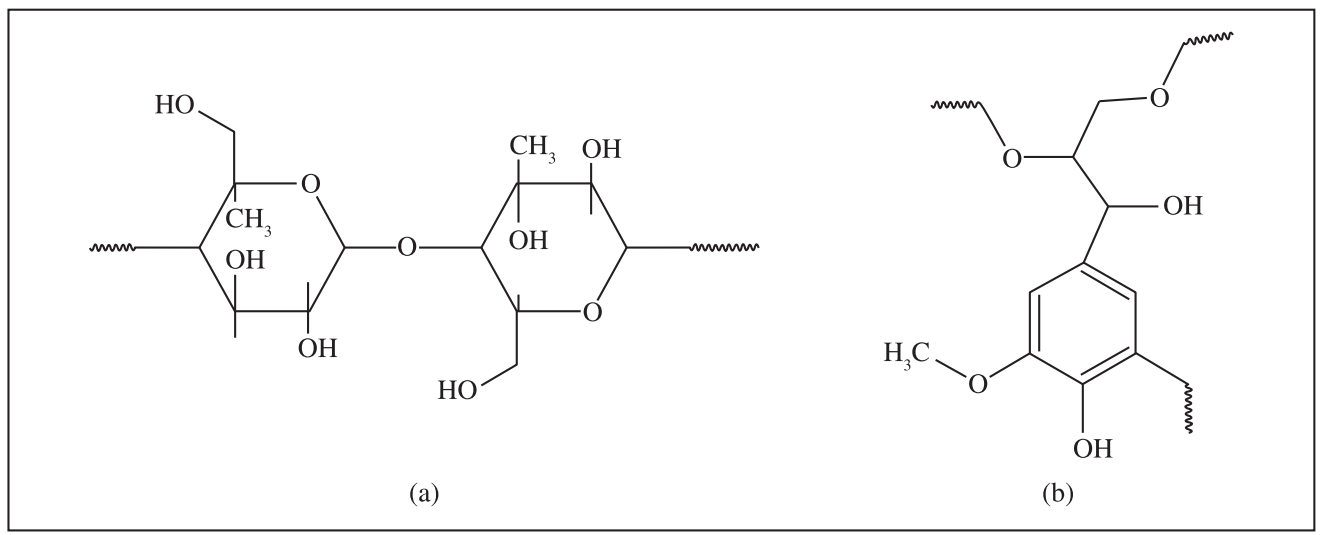

Figura 1. Estrutura química dos componentes das fibras vegetais: a) celulose, b) lignina ${ }^{[5,6]}$.

de relaxação nuclear que ocorrem na RMN são inerentes à espectroscopia, entretanto fornecem informações importantes sobre a dinâmica molecular ${ }^{[17-20]}$.

Martins et al. ${ }^{[21]}$ verificaram a eficiência dos tratamentos de modificação química (mercerização, acetilação e tratamento com resorcinol/hexametiltetramina) da fibra de sisal por RMN de alta resolução no estado sólido. Esta técnica permitiu visualizar as modificações na estrutura, como por exemplo, a acetilação das hidroxilas livres da fibra (formação do grupo éster), que leva a uma diminuição da hidrofilicidade da fibra. Capanema et al. ${ }^{[22]}$ estudaram a caracterização quantitativa da lignina das fibras naturais pela combinação das técnicas de ${ }^{1} \mathrm{H}-{ }^{13} \mathrm{C}$ heteronuclear multiple quantun coherence and quantitative (HMQC) que analisa as conectividades ${ }^{1} \mathrm{H}-{ }^{13} \mathrm{C}$. Outros trabalhos encontrados na literatura ${ }^{[1,18-22]}$ de análise de feijão, elastômeros e fibra de poliamida mostraram que a técnica de RMN no estado sólido é uma ferramenta eficaz na caracterização da estrutura e dinâmica molecular. Através destes trabalhos foi possível observar que essa técnica permitiu obter resultados da mobilidade da cadeia, ou seja, mostrou como os componentes da amostra estão organizados na cadeia, e a força de interação entre eles. No entanto, não foram encontrados na literatura cientifica artigos que mostram o estudo de morfologia das fibras naturais utilizando a técnica de relaxação nuclear ${ }^{1} \mathrm{H}$ (RMN no estado sólido de baixo campo).

Este trabalho tem como objetivo principal a avaliação do processo de relaxação longitudinal do núcleo hidrogênio (baixo campo) das fibras de bananeira e de coco, com vistas a caracterizar e estudar a organização estrutural dos componentes destas fibras.

\section{Parte Experimental}

\section{Obtenção das fibras}

\section{Fibra de bananeira}

Os troncos in natura de bananeira d'água (Musa sepientum) foram obtidos na região produtora de Rio Bonito, Estado do Rio de Janeiro. Os troncos de bananeira, chamados de pseudocaules, são formados por camadas, conhecidas como bainhas. Em cada bainha são identificados cinco diferentes tipos de fibras aqui denominadas "Fibra da extremidade limite" $\left(\mathrm{F}_{\text {lim }}\right)$, "Fibra da parte lateral externa" $\left(\mathrm{F}_{\text {Lext }}\right)$, "Fibra da parte interna" $\left(\mathrm{F}_{\text {int }}\right)$, "Fibra da parte intermediária" ( $\left.F_{\text {interm }}\right)$ e "Fibra da parte externa" $\left(F_{\text {ext }}\right)$. Foram utilizados neste trabalho as fibras " $F_{\text {int }}$ ", " $F_{\text {interm }}$ " e " $F_{\text {ext }}$ " que foram lavadas exaustivamente em água e, então, secas ao sol por 48 horas. Após a secagem, as fibras foram desagregadas e moídas em moinho de facas da marca Primotécnica, modelo LP 1003, e peneiradas até o tamanho de $0,15 \mathrm{~mm}$. Essas fibras foram escolhidas por apresentarem maior capilaridade em sua estrutura morfológica e, assim, permitir uma possível ancoragem física entre o polímero e a fibra. Outro fato importante para a escolha das fibras de bananeira foi a maior quantidade em massa fornecida por esses três tipos de fibra.

\section{Fibra de coco}

A fibra de coco foi cedida pela Embrapa/Ceará e disponibilizada já seca. As fibras foram moídas e peneiradas até o tamanho de $0,21 \mathrm{~mm}$.

\section{Caracterização das fibras}

As fibras de bananeira e de coco lavadas foram caracterizadas pelas técnicas de determinação do teor de lignina, espectrometria no infravermelho (FTIR) e por ressonância magnética nuclear no estado sólido. As fibras sem lignina foram caracterizadas pelas mesmas técnicas à exceção da determinação do teor de lignina.

\section{Quantificação de lignina}

A lignina foi extraída das fibras lavadas e secas e, então, quantificada. A extração da lignina das fibras de bananeira foi feita pelo método de Klason ${ }^{[23]}$. Esse método (Figura 2) visa à remoção dos polissacarídeos por solubilização em etanol e a lignina é extraída como resíduo por hidrólise ácida. A utilização do etanol/ benzeno tem como objtivo eliminar possíveis resinas presentes que possam mascarar a quantificação da lignina. As fibras sem lignina, após secagem em estufa por 16 horas, foram pesadas e o teor de lignina quantificado.

Teor de umidade

As fibras foram caracterizadas quanto ao teor de umidade. $\mathrm{O}$ procedimento foi efetuado em triplicata e consiste em pesar cerca de $2,00 \mathrm{~g}$ da fibra em recipiente tarado. $\mathrm{O}$ conjunto foi levado a estufa $\left(105 \pm 2{ }^{\circ} \mathrm{C}\right)$ por 3 horas, colocado no dessecador durante 30 minutos e finalmente pesado. Para aumentar a precisão e exatidão da análise o conjunto foi retornado à estufa por outros 30 minutos. A etapa de resfriamento e pesagem foi repetida até a obtenção da massa constante.

\section{Espectrometria no infravermelho com transformada de Fourier (FTIR)}

As análises foram conduzidas em um espectrômetro de absorção da marca Nicolet Magna $750 \mathrm{com}$ varredura de 4000 a $400 \mathrm{~cm}^{-1}$, resolução de 4000 e 16 scans. As amostras com e sem lignina das fibras de bananeira, "fibra da parte interna $\left(\mathrm{F}_{\text {int }}\right)$ ", "fibra da parte intermediária $\left(\mathrm{F}_{\text {interm }}\right)$ ", "fibra da parte externa $\left(\mathrm{F}_{\text {ext }}\right)$ " e a fibra de coco foram analisadas na forma de pastilhas prensadas com $\mathrm{KBr}$. 


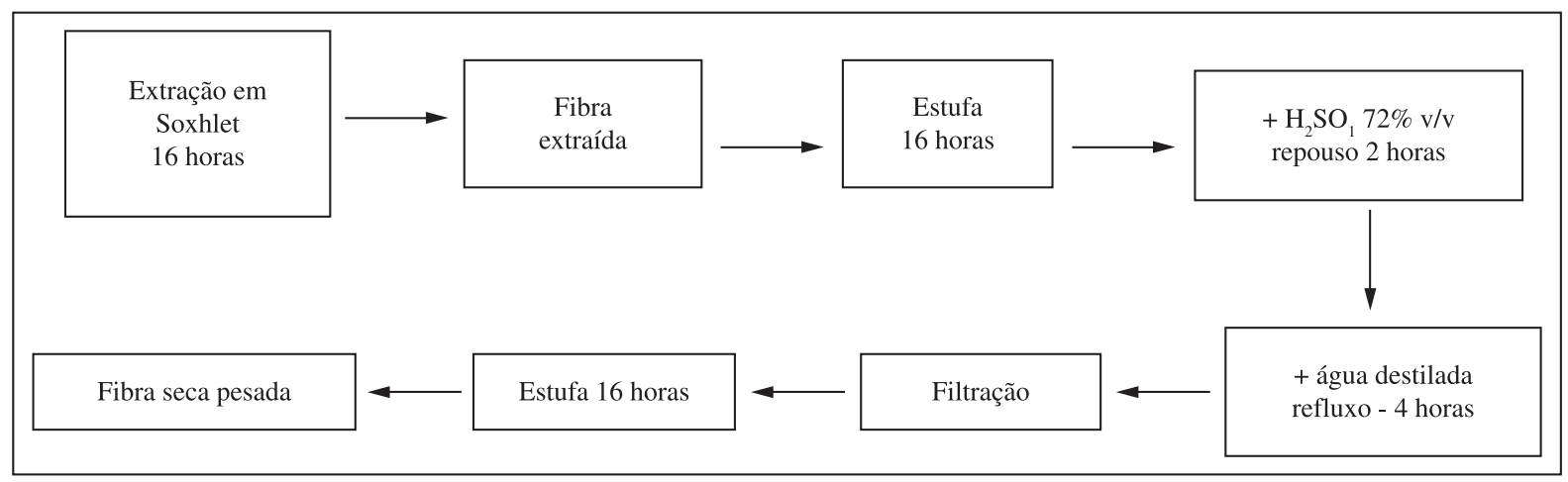

Figura 2. Procedimento de extração da lignina ${ }^{[23]}$.

\section{Medidas de Tempo de Relaxação $\left(\mathrm{T}_{1} \mathrm{H}\right)$}

A técnica de RMN no estado sólido foi escolhida por ser capaz de identificar as diferentes estruturas químicas existentes na fibra. Os três tipos de fibra da bananeira, "F $F_{\text {int }}$ ", "F $F_{\text {interm }}$ " e " $F_{\text {ext }}$ ", foram avaliados com relação aos tempos de relaxação.

As medidas dos tempos de relaxação longitudinal para os núcleos de ${ }^{1} \mathrm{H}\left(\mathrm{T}_{1}\right)$ foram obtidas através da técnica de inversãorecuperação. Esta técnica baseia-se na movimentação do vetor magnetização resultante, quando este é completamente invertido por meio de um pulso de $180^{\circ}$. Após um tempo de espera, necessário para que a magnetização retorne ao estado de equilíbrio, é aplicado um pulso de $90^{\circ}$, antecedendo a etapa de aquisição do sinal de RMN. Este alinhamento, conhecido como polarização, não é instantâneo e foi calibrado automaticamente em um intervalo de 4 até 4,3 segundos.

As medidas foram obtidas em um espectrômetro Maran Ultra $23 \mathrm{MHz}$ com frequiência do ${ }^{1} \mathrm{H}$ de $23 \mathrm{MHz}$ e com velocidade de rotação de $6 \mathrm{kHz}$, a temperatura ambiente de $27^{\circ} \mathrm{C}$. Foi obtido um número de 40 pontos e a análise foi feita em duplicata. $\mathrm{O}$ tempo de análise foi de 100-5000000 $\mu$ s. O intervalo entre cada tempo de espera foi de 5 segundos e foram realizadas quatro repetições.

\section{Resultados e Discussão}

\section{Avaliação do teor de lignina nas fibras}

A Tabela 1 mostra os percentuais de lignina e os desvios-padrão encontrados.

Os resultados da Tabela 1 mostram que as fibras de bananeira, independente do tipo, apresentaram valores de teor de lignina estatisticamente próximos. Contudo, os três tipos de fibras de bananeira ainda mostraram-se abaixo do teor encontrado para a fibra de coco.

Corradini et al. ${ }^{[24]}$ investigaram as características da fibra de coco verde de diversos locais de cultivo em relação à composição química, a fim de avaliar seu potencial de aplicação na elaboração de novos materiais. Os autores obtiveram os seguintes teores de lignina $37,2 \pm 0,8 \%$ a 43,9 $\pm 0,7 \%$ em massa. Essa variação se deve ao local de cultivo, ao ponto de maturação da fibra. Já Mendes ${ }^{[25]}$ encontrou para a fibra de coco um teor de $45 \%$ em massa de lignina.

$\mathrm{O}$ teor de lignina das fibras de bananeira depende da parte do pseudocaule analisada. Roja e Neves ${ }^{[7]}$ afirmam que encontraram na fibra de bananeira "Giant Cavendish" da parte " $F_{\text {interm }}$ " um baixo teor de lignina, $11,7 \%$ em massa. Coraiola e Mariotto ${ }^{[26]}$ encontraram na composição da fibra do mesmo tipo um teor de $12,7 \%$ em massa. Os valores encontrados na literatura estão de acordo com os valores achados pelos autores neste trabalho.
Tabela 1. Teor de lignina das fibras de coco e dos três tipos de fibras de bananeira.

\begin{tabular}{lc}
\hline Fibra & Teor de lignina (\% massa) \pm desvio padrão \\
\hline Coco & $44,6 \pm 4,0$ \\
"F $F_{\text {int }} "$ & $10,2 \pm 0,5$ \\
" $F_{\text {interm" }}$ & $14,0 \pm 4,0$ \\
" $\mathrm{F}_{\text {ext }}$ & $18,6 \pm 3,5$ \\
\hline
\end{tabular}

Tabela 2. Teor de umidade das fibras de coco e dos três tipos de fibras de bananeira.

\begin{tabular}{lc}
\hline Fibra & Teor de umidade (\% massa) \pm desvio padrão \\
\hline Coco & $20,0 \pm 0,5$ \\
"F $\mathrm{F}_{\text {int }} "$ & $22,0 \pm 0,5$ \\
"F $\mathrm{F}_{\text {interm" }}$ & $22,0 \pm 1,5$ \\
" $\mathrm{F}_{\text {ext }}$ & $19,0 \pm 2,0$ \\
\hline
\end{tabular}

\section{Avaliação do teor de umidade}

A Tabela 2 mostra os percentuais de umidade encontrados para as fibras de bananeira e de coco.

Com os resultados obtidos para o teor de umidade, conclui-se que as fibras de bananeira dos três tipos apresentaram teores de umidade iguais quando se leva em consideração os desvios-padrão. Gomes $^{[27]}$ encontrou um valor de teor de umidade médio para a fibra de bananeira do tipo prata de 11,4+0,3\% em massa.

Yamaji ${ }^{[28]}$ relata ter encontrado valores de umidade para as fibras lignocelulósicas de madeira na faixa de 10-18\% em massa.

Os teores de umidade encontrados para as fibras de bananeira e de coco (médio $21 \%$ em massa) estão bem mais elevados que os valores achados por outros autores na literatura. Isso se deve provavelmente a uma reabsorção de umidade das fibras, apesar de todo material ter sido seco por 48 horas e ter ficado em estufa.

\section{Espectrometria no Infravermelho (FTIR)}

A análise de FTIR foi feita para caracterizar os componentes químicos principais encontrados nas fibras de bananeira e de coco. Sabe-se que os principais componentes presentes na fibra são celulose, hemicelulose e lignina e que estes componentes apresentam em sua estrutura o grupo funcional hidroxila ${ }^{[5]}$. Este grupamento pode ser observado pela banda de absorção intensa na região de 3500 a $3000 \mathrm{~cm}^{-1}$. A presença de lignina é confirmada pelos sinais característicos de anel aromático em 2900 referente ao grupo alifático $\mathrm{CH}$ ligado ao anel e em $\sim 750 \mathrm{~cm}^{-1}$, banda referente a ligação $\mathrm{CH}$ fora do plano ${ }^{[29]}$. A Figura 3 mostra o espectro de FTIR das fibras com lignina e a Figura 4, das fibras sem lignina. Ao comparar as duas figuras, observa-se que nas regiões de absorção de 2900 e em $\sim 750 \mathrm{~cm}^{-1}$ houve uma diminuição nas bandas e uma 
baixa definição dos sinais, podendo-se concluir que a retirada da lignina foi eficiente.

\section{Medidas de relaxação longitudinal $\left(T_{1} H\right)$}

A Tabela 3 mostra os resultados obtidos de tempos de relaxação $\left(\mathrm{T}_{1} \mathrm{H}\right)$ das fibras de coco e de bananeira com lignina e a Figura 5 mostra as curvas com os diferentes domínios encontrados para as fibras de coco e de bananeira com lignina.

Os tempos de relaxação obtidos, pelo decaimento monoexponencial, para as fibras de bananeira e de coco com lignina mostraram a presença de três domínios principais. O primeiro domínio, mais móvel, relativo à umidade presente nas fibras naturais e o segundo domínio, largo e sem definição, referente aos componentes da fibra (celulose, hemicelulose) e o terceiro domínio, menos móvel, demorando mais tempo para relaxar é referente à lignina.

Por meio dos tempos de relaxação dos núcleos de ${ }^{1} \mathrm{H}$ das fibras é possível acompanhar as mudanças ocorridas na estrutura da fibra. Também é possível relacionar os teores de lignina existentes nas fibras com a capacidade da estrutura relaxar, ou seja, mede-se o tempo que o spin excitado leva para voltar para seu estado fundamental.

Os teores de umidade não serão relacionados, pois todas as fibras apresentaram valores muito próximos, não sendo possível

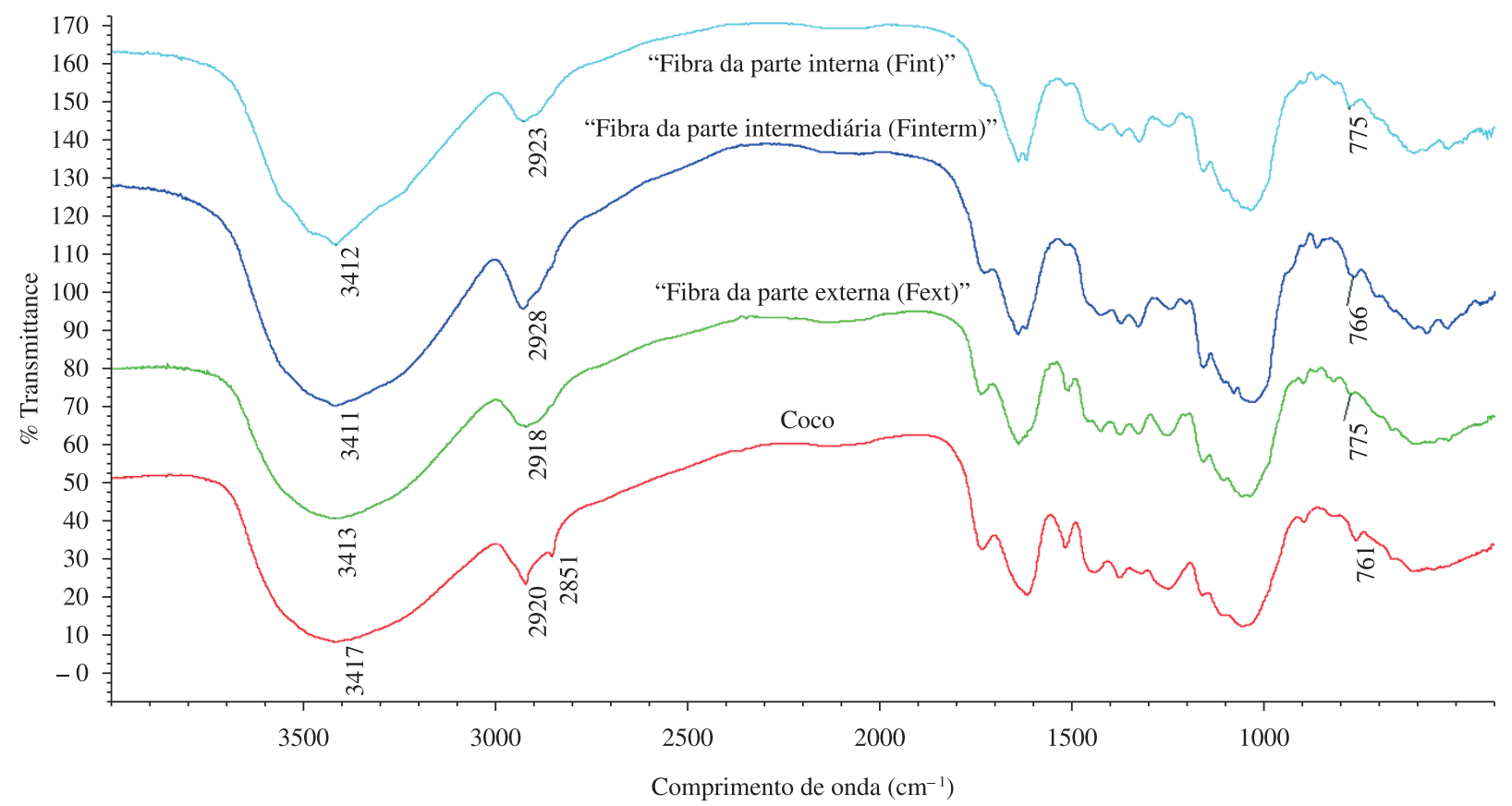

Figura 3. Espectro de infravermelho das fibras de bananeira e de coco com lignina.

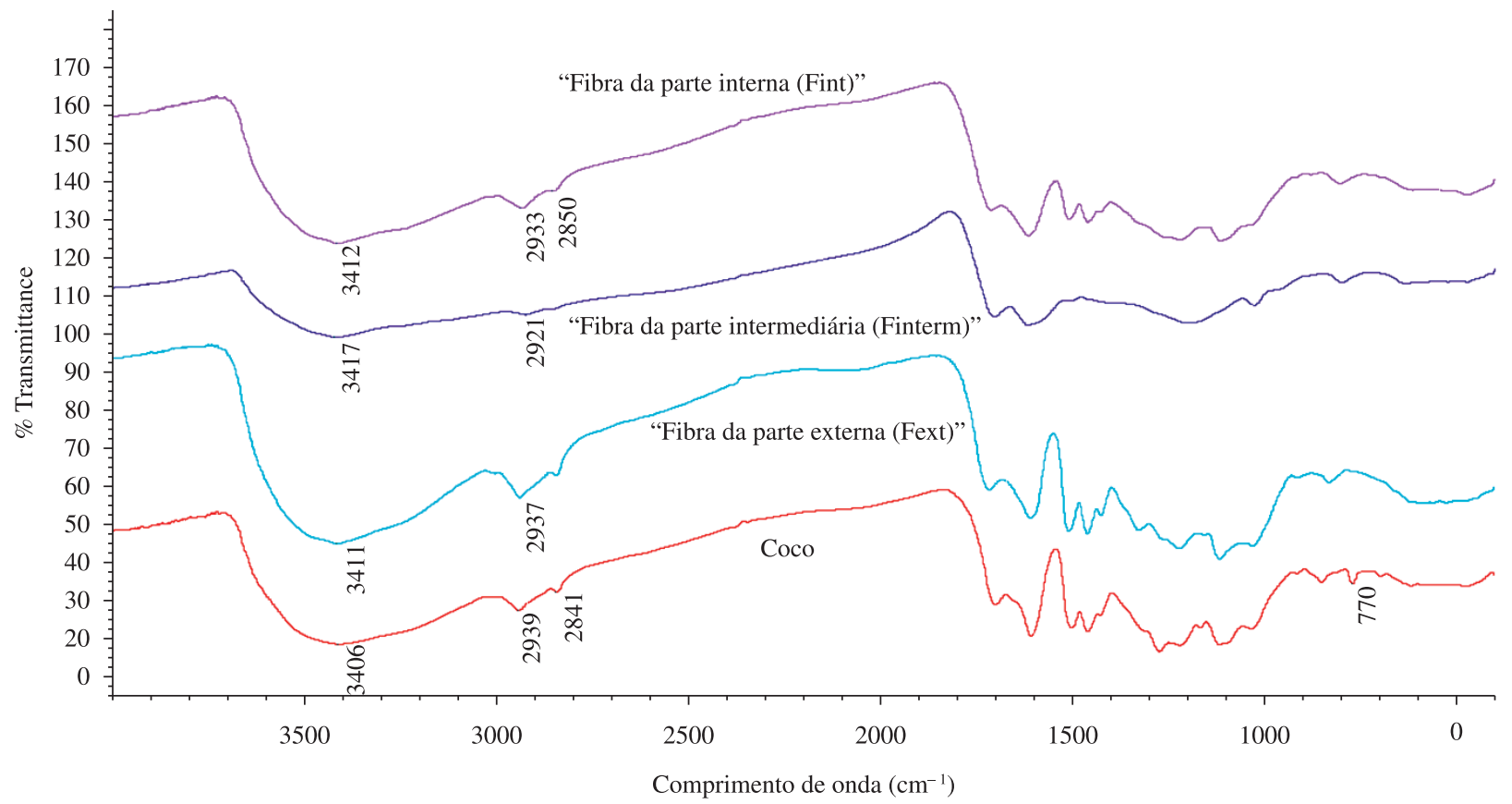

Figura 4. Espectro de infravermelho das fibras de bananeira e de coco sem lignina 
utilizar o resultado como forma de comparação. A presença de água na estrutura da fibra ${ }^{[30-32]}$ confere uma mobilidade à estrutura, ou seja, a água atua como um plastificante na estrutura do polímero natural. A água possui apenas dois hidrogênios $\left({ }^{1} \mathrm{H}\right)$ tendo, assim, um domínio mais móvel e um menor tempo de $T_{1} H$. Então, quanto maior for o teor de umidade da fibra maior será sua mobilidade molecular devido ao maior grau de liberdade molecular.

A lignina apresenta uma estrutura molecular mais rígida e entrelaçada devido à presença dos anéis aromáticos. Esses anéis conferem à estrutura uma baixa mobilidade estrutural, uma alta estabilidade térmica e boas propriedades mecânicas ${ }^{[16]}$. À medida que o teor de lignina aumenta na fibra, ocorre um aumento do tempo de relaxação, ou seja, ocorre um enrijecimento das cadeias devido a uma reorganização molecular. Isso ocorre porque a lignina tem uma constituição fenólica que atua como agente enrijecedor para as moléculas de celulose dentro da parede da fibra, mantendo-as unidas ${ }^{[5]}$. Sendo assim, é possível concluir que a fibra de coco possui um maior tempo de relaxação, pois apresenta em sua composição $44 \%$ em massa de lignina. Já as fibras de bananeira dos tipos " $F$ int $\mathrm{e}$ "F $F_{\text {interm }}$ " possuem um menor teor de lignina, apresentando um tempo de relaxação curto, indicando que apresentam uma alta mobilidade.

A "Fibra da parte externa" possui um tempo de $\mathrm{T}_{1} \mathrm{H}$ um pouco maior que as fibras de bananeira " $F_{\text {int }}$ " e " $F_{\text {interm }}$ " por apresentar em sua estrutura aproximadamente $19 \%$ em massa de lignina, o que confere a esta fibra uma rigidez maior da cadeia e, consequentemente, menor mobilidade, acarretando em domínios com tempos de relaxação maiores.

Tabela 3. Tempos de relaxação $\mathrm{T}_{1} \mathrm{H}$ no eixo rotatório para as fibras de bananeira e de coco com lignina.

\begin{tabular}{lcc}
\hline Fibra & \multicolumn{2}{c}{ T1(ms) } \\
\cline { 2 - 3 } & Água & Lignina \\
\hline Coco & 3 & 78 \\
"F $F_{\text {int }}$ & - & 17 \\
"F $\mathrm{F}_{\text {interm }}$ & - & 12 \\
" $\mathrm{F}_{\text {ext }}$ & - & 28 \\
\hline
\end{tabular}

As análises dos valores de $\mathrm{T}_{1} \mathrm{H}$ mostraram que as amostras de fibras possuem uma estrutura molecular complexa, ou seja, as fibras possuem constituintes com um alto grau de entrelaçamento, o que dificulta a separação desses componentes, acarretando em picos sobrepostos e com uma baixa definição. Para tentar melhorar a separação dos picos e a resolução das curvas de domínio, aumentou-se a janela espectral para 10 milhões, mas o resultado obtido não foi melhor, os picos ficaram mais alargados e não foi possível a identificação do pico referente à lignina.

Então se conclui que as fibras com maiores teores de lignina apresentam tempos de relaxação nuclear maiores. Este aumento no valor do tempo de relaxação deve-se ao aumento da rigidez das cadeias. Para comprovar esses resultados foram feitas análises dos tempos de relaxação, pelo método de decaimento monoexponencial, das fibras sem lignina.

A Figura 6 apresenta as curvas com os diferentes domínios e tempos de relaxação de $\mathrm{T}_{1} \mathrm{H}$ para as fibras sem lignina.

Por meio das curvas é possível observar uma melhor definição e separação dos picos, podendo-se relacionar os componentes presentes na estrutura da fibra com cada domínio obtido pela técnica de determinação do $\mathrm{T}_{1} \mathrm{H}$.

$\mathrm{Na}$ análise do tempo de relaxação das fibras com lignina, observou-se uma sobreposição de picos, não sendo possível identificar os domínios referentes à celulose e à hemicelulose. $\mathrm{O}$ único domínio que apresentou uma boa separação foi o domínio referente ao da lignina.

Ao retirar a lignina das fibras acredita-se que houve uma reorganização estrutural, de tal forma que as interações entre a celulose e a hemicelulose tornaram-se mais fáceis de acontecer, levando a um aumento no grau de cristalização. Essa nova organização permite identificar e relacionar os domínios com os componentes das fibras, sendo o primeiro e menor domínio identificado como o da água, o segundo é, provavelmente, da hemicelulose e o terceiro, da celulose. A única fibra que não teve a formação de três domínios foi a "Fibra da parte interna".

Outra observação importante diz respeito ao tempo de relaxação das fibras sem lignina que foram maiores que os das fibras com

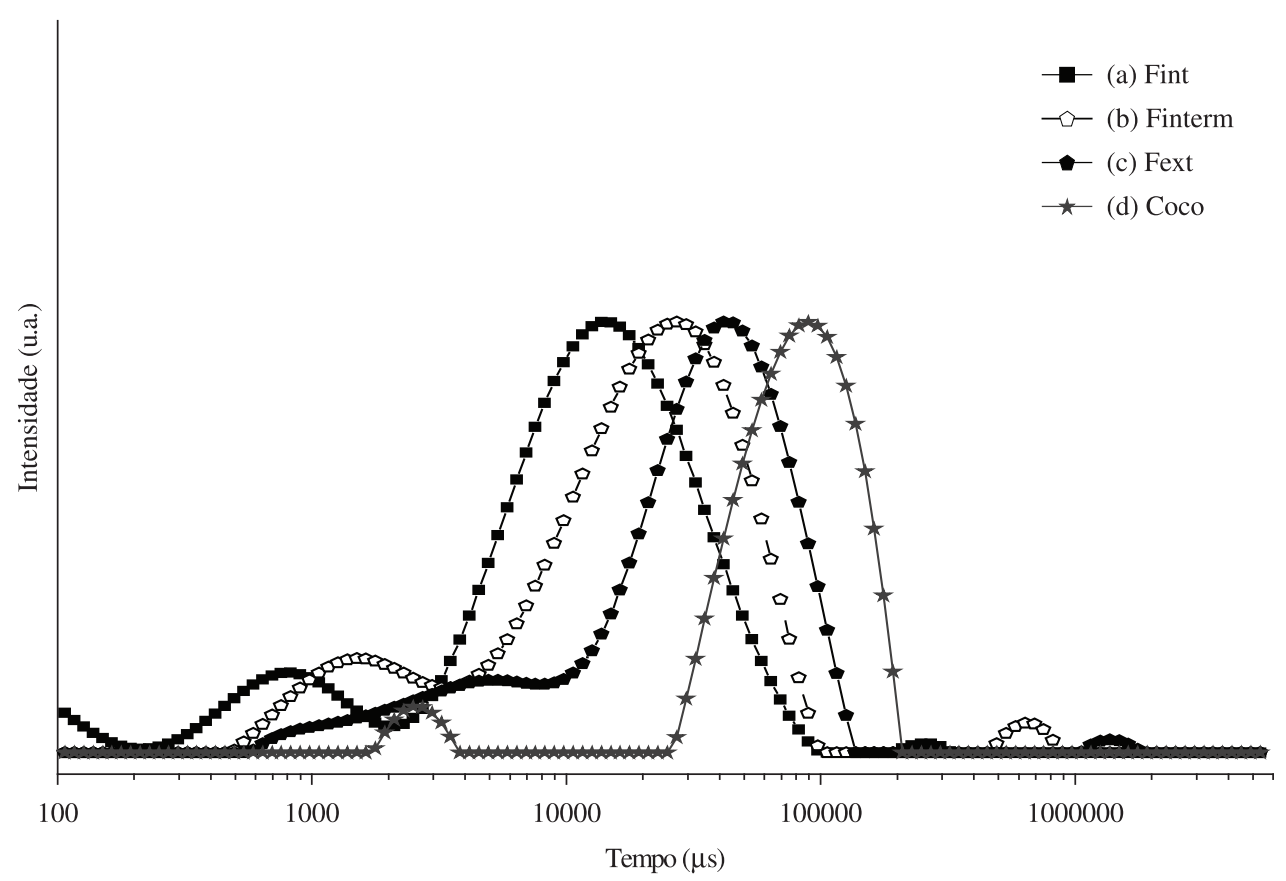

Figura 5. Curvas dos domínios de relaxação das fibras com lignina: (a) "Fibra da parte interna $\left(\mathrm{F}_{\mathrm{int}}\right)$ "; (b) "Fibra da parte intermediária $\left(\mathrm{F}_{\text {interm }}\right)$ "; (c) "Fibra da parte externa ( $\left.\mathrm{F}_{\text {ext }}\right)$ "; (d) Fibra do coco. 


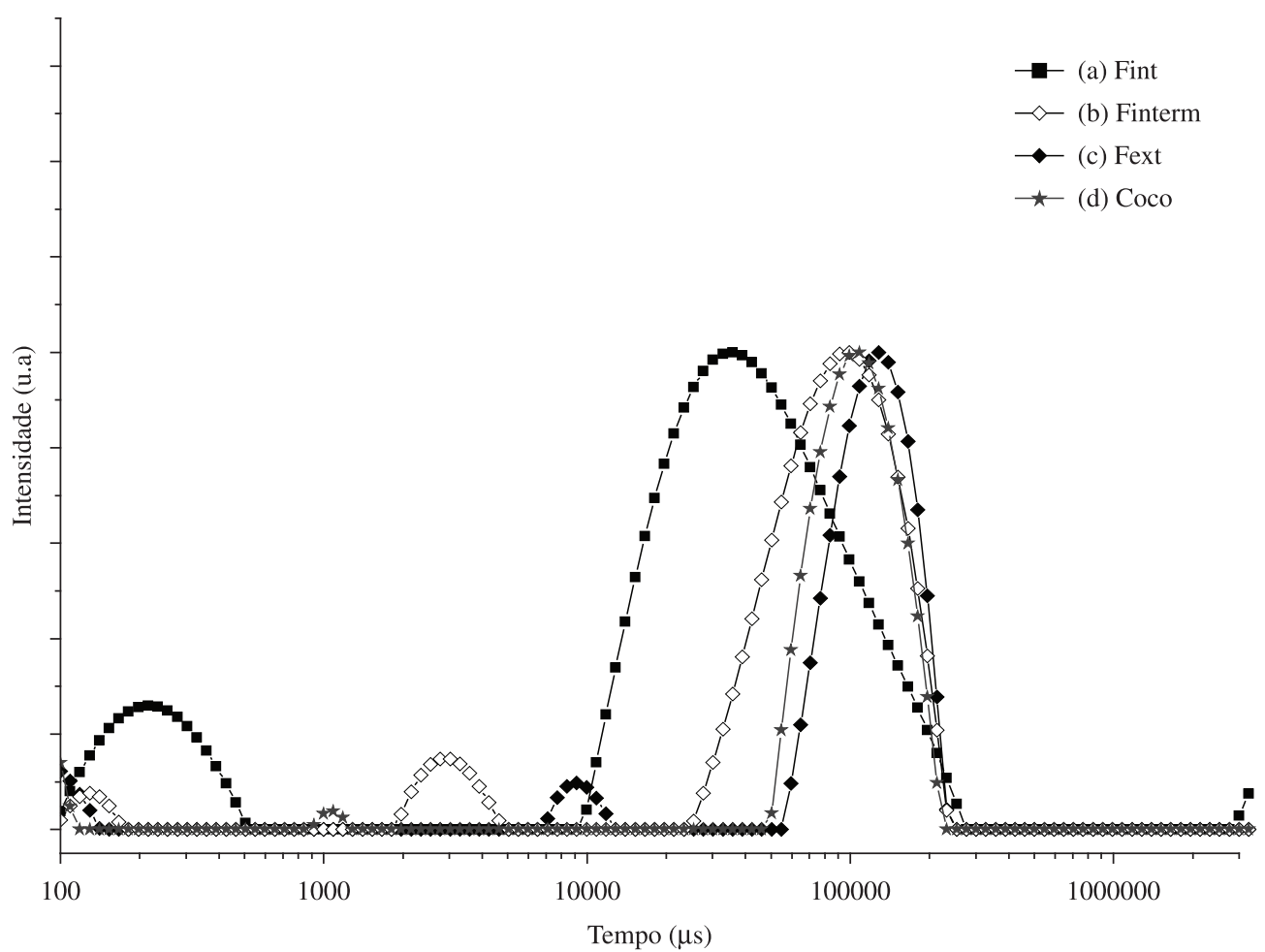

Figura 6. Curvas dos domínios de relaxação das fibras sem lignina: (a) "Fibra da parte interna"; (b) "Fibra da parte intermediária"; (c) "Fibra da parte externa"; (d) "Coco".

lignina, provavelmente devido à cristalização das fibras na ausência da lignina. A cristalização ocorre quando as moléculas encontram condições favoráveis e, de modo geral, torna o material mais resistente. No caso das fibras, o favorecimento para a ocorrência de interações intermoleculares faz com que a fibra demore mais tempo para relaxar e retornar ao seu estado fundamental. Com isso, os tempos de relaxação foram maiores para todas as fibras, fibra de coco $(104 \mathrm{~m} / \mathrm{s})$, "Fibra da parte interna" $(41 \mathrm{~m} / \mathrm{s})$, "Fibra da parte intermediária" (79 m/s) e "Fibra da parte externa" (113 m/s).

Sendo assim, a técnica de determinação do tempo de relaxação é uma ferramenta que pode ser usada na investigação sobre o comportamento dos diferentes componentes de uma fibra, com relação à sua mobilidade.

\section{Conclusão}

As análises de RMN no estado sólido revelaram que as fibras com maiores teores de lignina em sua composição apresentam maior rigidez molecular e consequentemente maiores tempos de relaxação dos núcleos de $\mathrm{H}$, em face das interações intermoleculares e arranjos organizacionais das cadeias.

Aparentemente, com a retirada da lignina ocorre uma reorganização estrutural das cadeias carbônicas da celulose e da hemicelulose, o que faz com que elas sejam mais rígidas e tenham tempos de relaxação maiores. As fibras sem lignina podem, então, interagir mais facilmente, levando a uma maior cristalização, tornando-se assim mais resistentes e fornecendo tempos de relaxação bem maiores que as fibras com lignina. A lignina, embora se constitua no elemento enrijecedor das fibras, já que contém em sua estrutura anéis aromáticos, é a parte amorfa da fibra. Com a sua retirada, o material fibroso passa a ter um conteúdo cristalino maior, tornando mais fácil a identificação e a relação dos domínios com os componentes das fibras. Dessa forma, a partir de ensaios de RMN foi possível observar a presença de cristalinidade e a organização morfológica das estruturas químicas das fibras.

A técnica de relaxação nuclear é uma ferramenta eficaz na identificação da interação dos componentes presentes na fibra, o que pode ser muito útil em uma etapa posterior de modificação da estrutura da fibra e fabricação de compósito com uma matriz polimérica apolar.

\section{Agradecimentos}

Os autores agradecem às agências de fomento CNPq, CAPES e FAPERJ, às Empresas Haztec Tecnologia e Planejamento Ambiental S.A., Koleta Ambiental S.A. e Centro de Reciclagem Rio (CRR) e à Cooperativa CoopFibra - Rio Bonito pela doação dos troncos de bananeira.

\section{Referências Bibliográficas}

1. Lião, L. M.; Choze, R.; Cavalcante, P. P. A.; Santos, S. C.; Ferri, P. H. \& Ferreira, A. G. - Quim. Nova, 33, p.634 (2010). http://dx.doi. org/10.1590/S0100-40422010000300028

2. Stael, G. C. \& Tavares, M. I. B. - J. Appl. Polym. Sci., 82, p.2150 (2001). http://dx.doi.org/10.1002/app.2061

3. Rodrigues, T. C.; Tavares, M. I. B.; Preto, M.; Soares, I. L. \& Moreira, A. C. F. - Int. J. Polym. Mat., 57, p. 1119 (2008).

4. Tang, H.\& Hills, B. P. - Biomacromolecules, 4, p.1269 (2003). http:// dx.doi.org/10.1021/bm034074p

5. Fowler, P. A.; Hughes, J. M. \& Elias, R. M. - J. Sci. Food Agr., 86, p. 1781 (2006). http://dx.doi.org/10.1002/jsfa.2558

6. Regiani, A. M. - "Eletrólitos sólidos poliméricos à base de polissacarídeos: síntese e caracterização", Tese de Doutorado, Universidade Federal de São Carlos, Brasil (2000).

7. Roja, M. L. B. \& Neves, J. M. - "Caracterização de fibras de bananeira "Nanicão" (Musa Grupo AAA, "Giant Cavendish") como possível 
matéria-prima para produção de pasta celulósica para fabricação de papel", in: Anais do Congreso Iberoamericano de Investigación em Celulosa y Papel, Campinas - SP (2002).

8. Joseph, P. V.; Rabello, M. S.; Mattoso, L. H. C.; Joseph, K. \& Thomas, S. - Compos. Sci. Tech., 62, p.1357 (2002). http://dx.doi.org/10.1016/ S0266-3538(02)00080-5

9. Coelho, R. R. P.; Mata, M. E. R. M. C. \& Braga, M. E. D. - Rev. Bras. Prod. Agroind., 3, p.21, (2001).

10. Suddell, B. C. \& Evans, W. J. "A Survey into the Application of Natural Fiber Composites in the Automotive Industry", in: Anais do International Symposium on Natural Polymers and Composites, São Pedro, Brasil (2002).

11. Dahlke, B.; Larbig, H.; Scherzer, H. D. \& Poltrock, R. - J. Cell. Plast., 34, p.361 (1998). http://dx.doi.org/10.1177/0021955X9803400406

12. Da Silva, R. V.; Aquino, E. M. F.; Rodrigues, L. P. S. \& Barros, A. R. F. - Matéria, 13, p.154 (2008).

13. Colom, X.; Carrasco, F.; Pages, P. \& Canavate, J. - Compos. Sci. Tech., 63, p.161 (2003). http://dx.doi.org/10.1016/S02663538(02)00248-8

14. Spinacé, M. A. S.; Lambert, C. S.; Fermoselli, K. K. G. \& De Paoli, M.A. - Carbohyd. Polym., 77, p.47 (2009). http://dx.doi.org/10.1016/j. carbpol.2008.12.005

15. Martins, M. A.; Mattoso, L. H. C. \& Pessoa, J. D. C. - Rev. Bras. Frutic., 31, p.1150 (2009). http://dx.doi.org/10.1590/S010029452009000400032

16. Tita, S. P. S.; Paiva, J. M. F. \& Frollini, E. - Polímeros, 12, p.228 (2002). http://dx.doi.org/10.1590/S0104-14282002000400005

17. Escher, F. F. N. - "Determinação da microestrutura e relação com as propriedades dos termopolímeros de etileno-propileno- $\alpha$-olefinas", Tese de doutorado, Universidade Federal do Rio Grande do Sul, Brasil (2008).

18. Gil, V. M. S. \& Geraldes, C. F. G. C. - "Ressonância Magnética nuclear - Fundamentos, Métodos e Aplicações”, Fundação Calouste Gulbenkian, Lisboa (1987).

19. Tavares, M. I. B. \& Silva, N. M. - Polímeros, 4, p.40 (1994).

20. Silva, A. M. - "Caracterização do processo de degradação de uma fibra de poliamida utilizada como meio filtrante na indústria mineral", Dissertação de mestrado, Universidade Federal de Ouro Preto, Brasil (2000).
21. Martins, M. A.; Forato, L. A.; Mattoso, L. H. C. \& Colnago, L. A. - Carbohyd. Polym., 64, p.127 (2006). http://dx.doi.org/10.1016/j. carbpol.2005.10.034

22. Capanema, E. A.; Balakshin, M. Y. \& Kadla, J. F. - J. Agric. Food Chem., 52, p.1850 (2004). http://dx.doi.org/10.1021/jf035282b

23. Saliba, E. O. S.; Rodriguez, N. M.; Morais, S. A. L. \& Pilo-Veloso, D. - Ciên. Rural, 31, p.917 (2001). http://dx.doi.org/10.1590/S010384782001000500031

24. Corradini, E.; Rosa, M. F.; Macedo, B. P.; Paladin, P. D. \& Mattoso, L. H. C. - Rev. Bras. Frutic., 31, p.837 (2009). http://dx.doi.org/10.1590/ S0100-29452009000300030

25. Mendes, J. - "Desenvolvimento de um composto biodegradável para isolamento térmico", Tese de Doutorado. Universidade Federal do Rio Grande do Norte, Brasil (2002)

26. Coraiola, M. \& Mariotto, S. C. - Rev. Acad., Ciênc. Agrár. Ambient., 7, p.207 (2009)

27. Gomes, T. S. - "Obtenção e avaliação das propriedades mecânicas e térmicas de compósitos a base de polietileno de alta densidade e fibras de bananeira", Dissertação de Mestrado, Universidade Federal do Rio de Janeiro, Brasil (2010).

28. Yamaji, F. M. - "Produção de compósito plástico-madeira a partir de resíduos da indústria madeireira", Tese de doutorado, Universidade Federal do Paraná, Brasil (2004)

29. Silverstein, M. R.; Bassler C. G. \& Morrill C. T. - "Identificação espectrométrica de compostos orgânicos", Livros Técnicos e Científicos S.A., Rio de Janeiro (1994).

30. Carrijo, O. A.; Liz, R. S. \& Makishima, N. - Hortic. Bras., 20, p.533 (2002). http://dx.doi.org/10.1590/S0102-05362002000400003

31. Sreekala, M. S. \& Thomas, S. - Compos. Sci. Tech., 63, p.861 (2003). http://dx.doi.org/10.1016/S0266-3538(02)00270-1

32. Barros, A. R. F.; Aquino, E. M. F.; Rodrigues, L. P. S. \& Silva, R. V. - "Laminados compósitos a base de fibras natural e sintética: efeito de condições ambientais adversas", in: Anais do $17^{\circ}$ Congresso Brasileiro de Engenharia e Ciência dos Materiais, Foz do Iguaçu - PR, Brasil (2006).

Enviado: 12/05/11

Reenviado: 08/12/11

Aceito: 03/01/12 